\title{
Título: USO DE DROGAS PARA RENDIMENTO NO FISICULTURISMO E DOENÇAS ASSOCIADAS: UMA REVISÃO DE ESTUDOS DE CASO.
}

\author{
Maia $\mathrm{AM}^{1}$; Oliveira Neto $\mathrm{JV}^{2}$; Caminha JSR ${ }^{3}$; Nunes Filho JCC ${ }^{4}$; Aragão GCB ${ }^{5}$; \\ Pinto DV ${ }^{6}$. \\ ${ }^{1}$ Instituto de Educação Física e Esportes, UFC, Fortaleza-CE. \\ ${ }^{2}$ Instituto de Educação Física e Esportes, UFC, Fortaleza-CE. \\ ${ }^{3}$ Instituto de Educação Física e Esportes, UFC, Fortaleza-CE. \\ ${ }^{4}$ Ciências Médicas, UFC, Fortaleza-CE. \\ ${ }^{5}$ Instituto de Educação Física e Esportes, UFC, Fortaleza-CE. \\ ${ }^{6}$ Ciências Médicas, UFC, Fortaleza-CE.
}

\section{Linha de pesquisa: Biologia para Saúde}

Introdução: O fisiculturismo é uma atividade que visa moldar o corpo, construindo uma estética corporal mais hipertrofiada e com baixo índice de gordura. No entanto, sabe-se que dentro da competição de fisiculturismo, corriqueiramente existe o uso ilícito de substâncias que visam alavancar os ganhos, permitindo ao atleta um resultado mais rápido e pronunciado. Contudo, é relevante que se fale sobre os possíveis danos que o uso de esteroides anabolizantes pode vir a causar. $\mathrm{Na}$ busca de construir conhecimento científico sobre o tema é possível utilizar-se dos vários casos médicos que reportam entradas de pacientes em hospitais devido acometimentos decorrentes do uso de tais substâncias, muitas vezes expressadas somente como esteroides anabolizantes, dessa forma torna-se justificável rever os casos clínicos que reportam cientificamente diagnósticos de pessoas que na busca por manterem essa estética acabaram por sacrificar sua saúde. Objetivos: Elucidar sobre um apanhado sistemático de estudos de casos de fisiculturistas com enfermidades relacionadas ao uso ilícito de substâncias. Métodos: Foi realizada uma busca na base de dados PubMed, nos meses de março e abril de 2017, onde procurou-se artigos de no máximo 15 anos. Foi usada a seguinte junção de termos de busca: steroid AND bodybuilder. Após a colocação de todos filtros necessários e seguido critérios pré-estabelecidos, restaram 32 artigos, dos quais somente um não pode ser acessado. Foi feita então a leitura dos outros 31 que puderam ser acessados, e então construída uma tabela descritiva dos sujeitos que foram estudados, atentando-se a idade, drogas usadas e diagnósticos apontados. O software SPSS versão 22 (IBM) foi utilizado para análise dos dados. Resultados: Os sujeitos relatados nos estudos de caso tinham entre 16 e 50 anos de idade (média: 31,87 $\pm 8,21$ ), e algumas das drogas usadas foram: Androstenediona, Decanoato de Nandrolona, Enantato de Testosterona, Estanozolol, GH Bovino, Metadrostrenolona, Nandrolona, Oxandrolona, Oximetolona, Sustanon, Acetato de Trembolona, Metenolona, Testosterona, GH, Metadienona, Proprionato de Drostanolona, Trenabol, Clenbuterol, Eritropoetina, Cytomel e Enantato de Trembolona. Sendo os três mais usados: Estanozolol, Nandrolona (DECA) e Enantato de Testosterona. Houve também 5 estudos que não especificaram qual substância foi usada, e 2 em que os pacientes relataram não uso. Alguns diagnósticos estabelecidos foram: Carcinoma hepatocelular, Cardiomiopatia de Takotsubo, Nefropatia do ácido biliar, Nefrocalcinoses, Infarto Renal, Baixo nível de testosterona, Acne fulminante, Síndrome compartimental, Infarto Agudo do Miocárdio, Rabdomiólise, Adenoma hepático, Pancreatite aguda, Insuficiência Hepática Aguda entre 
outros. Conclusão: O estudo mostrou uma gama de substâncias utilizadas por fisiculturistas, e também, as doenças associadas ao uso destes. Os profissionais da área da saúde devem trabalhar de forma conjunta para conscientização e esclarecimento acerca do uso de substâncias ilícitas para o rendimento, pois é visto que este pode levar seus usuários a quadros clínicos delicados e perigosos. Dessa forma, o trabalho multidisciplinar, bem como a atenção hospitalar, deve ser objetivado tanto no sistema público como particular de saúde. Apoio Financeiro: O presente estudo não teve nenhum apoio financeiro. 